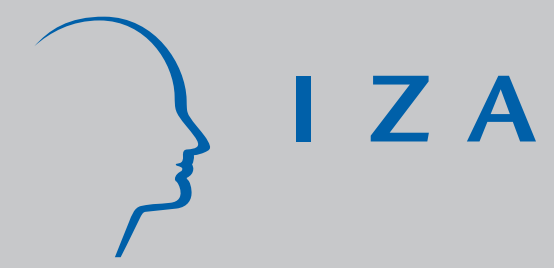

IZA DP No. 1439

Specialisation Patterns and the Synchronicity of Regional Employment Cycles in Europe

Ansgar Belke

J ens M. Heine

December 2004 


\title{
Specialisation Patterns \\ and the Synchronicity of Regional Employment Cycles in Europe
}

\author{
Ansgar Belke \\ University of Hohenheim \\ and IZA Bonn \\ Jens M. Heine \\ zeb/rolfes.schierenbeck.associates
}
Discussion Paper No. 1439
December 2004

\author{
IZA \\ P.O. Box 7240 \\ 53072 Bonn \\ Germany \\ Phone: +49-228-3894-0 \\ Fax: +49-228-3894-180 \\ Email: iza@iza.org
}

\begin{abstract}
Any opinions expressed here are those of the author(s) and not those of the institute. Research disseminated by IZA may include views on policy, but the institute itself takes no institutional policy positions.
\end{abstract}

The Institute for the Study of Labor (IZA) in Bonn is a local and virtual international research center and a place of communication between science, politics and business. IZA is an independent nonprofit company supported by Deutsche Post World Net. The center is associated with the University of Bonn and offers a stimulating research environment through its research networks, research support, and visitors and doctoral programs. IZA engages in (i) original and internationally competitive research in all fields of labor economics, (ii) development of policy concepts, and (iii) dissemination of research results and concepts to the interested public.

IZA Discussion Papers often represent preliminary work and are circulated to encourage discussion. Citation of such a paper should account for its provisional character. A revised version may be available directly from the author. 
IZA Discussion Paper No. 1439

December 2004

\section{ABSTRACT}

\section{Specialisation Patterns and the Synchronicity of Regional Employment Cycles in Europe}

This paper examines the degree of correlation of EU regional employment cycles and attempts to show whether these cycles reflect changing patterns of specialisation. By focusing on the regional level and by employing three different indicators of similarity of sectoral structure, it improves on existing studies. A dynamic panel data model is estimated pairs of regions by within groups, i.e., by a standard fixed effects estimator. Special attention is paid to capture the rich dynamics which are typical of employment data. The key finding is that employment growth is more synchronised when regions look alike in their sectoral structure.

JEL Classification: E32, F15, R23

Keywords: regional employment, European Union, regional business cycles, specialisation, synchronicity

Corresponding author:

Ansgar Belke

Department of Economics

Universität Hohenheim

70593 Stuttgart

Germany

Email: belke@uni-hohenheim.de 


\section{Introduction}

The integration of nations within Europe has been an important issue for four decades now. With respect to the national level, there exists a variety of empirical studies focussing on the similarities and differences in sectoral structures (for example, the level of national specialisation or its inverse, the level of similarity), the sources of national business cycles and the importance of industry-specific shocks. Considerable theoretical and empirical research on this general issue has been conducted, but this line of research has usually emph asised differences across countries, assuming implicitly (instead of testing explicitly) that countries themselves are homogenous entities. Although the implicit assumption of homogenous entities is not warranted, still very few studies combine measures of regional instead of national specialisation with the co-movement of regional business cycles. In this paper we explore the relationship between regional employment cycles and the similarity of bilateral regional sectoral structures, and empirically test the hypothesis that the similarity of regional industrial patterns enhances the bilateral correlation of regional emplo yment cycles.

The remainder of this article is organised as follows. In section 2, we motivate our study based on a survey of the empirical literature which deals with the determinants of the synchronicity of European national and regional employment cycles. In section 3, we explain the specification of the relevant variables in detail and give some inform ation about the data sources. Above all, we provide an in-depth-discussion of the construction as well as the relative merits of several alternative bilateral indicators, measuring the degree of similarity between the sectoral structures of two regions. We also deliver some stylised facts about the potential correlation between regional business cycle synchronisation, the degree of regional similarity in the sectoral structure and about the r esults of panel unit root tests. In section 4 , we introduce the empirical model, describe and give reasons for the chosen estimation procedure and discuss the empirical results of the conducted panel regressions. The empirical 
method adopted is to estimate a dynamic panel data model for region-pairs by within groups, i.e., by a standard fixed effects estimator. This model relates (rolling) correlations between regional employment cycles to a measure of sectoral similarity and to differences between regional incomes. Special attention is paid to capture the rich dynamics typically inherent in employment data. We also test whether our results are robust to the inclusion of additional variables. In section 5, we summarise our findings and draw some policy conclusions. Our key finding is that employment growth is indeed more synchronised in a statist ically significant way when regions have a more identical sectoral structure. This evidence is robust with respect to the inclusion of additional variables such as differences in incomes between regions and to different specifications of specialisation indices.

\section{Motivation}

The increasing synchronicity of national business cycles within Europe has been investigated empirically by many authors, identifying the start of the European Monetary Sy stem (EMS) in 1979 (Artis and Zhang, 1997), the increase in international trade (Frankel and Rose, 1998), identical income and sectoral structures between two economies (Imbs, 1999) or the existence of a common border (Clark and Wincoop, 2001) as the main reasons for this phenomenon.

Artis and Zhang (1997) investigate the national business cycles of different countries and approximate these cycles with the filtered time series of industrial production. They regress these time series on a U.S. as well as on a German benchmark cycle. Their main result is that continental European countries display a business cycle beha viour which has become increasingly synchronised to the German cycle and less to the U.S. cycle especially since the creation of the EMS in 1979. Based on his own analysis, Fatás (1997) also concludes that the synchronicity of regional business (employment) cycles to a hypothetical European ag- 
gregate has increased since the start of the EMS. Although measuring business cycle synchronisation using employment growth is not ideal, he applies the growth rate of emplo yment within a region instead of regional GDP growth as an indicator of its business c ycle stance. The main arguments in favour of the former are the following: (a) regional emplo yment growth is strongly correlated with real GDP growth, (b) data revisions are less fr equent for employment growth, (c) regional employment data can be aggregate d more easily than regional GDP data (e.g., adequate bookkeeping of regional exports and imports), and employment growth is the politically relevant var iable. ${ }^{1}$ Fatás (1997) as well as Forni and Reichlin (1997) and Barrios et al. (2001) were among the first to stress the potential importance of the regional dimension. Both Fatás (1997) and Artis and Zhang (1997) emphasise the role of the exchange rate regime in determining the cyclical behaviour of macroec onomic time series and the degree of bilateral correlation of business cycles. These studies focus on the role of a nominal variable, but neglect the impact of real variables on the degree of synchronicity.

Focusing on different real impact variables, Frankel and Rose (1998) examine the influences of aggregated foreign trade on the synchronicity of national business cycles. They draw the conclusion that an increase in foreign trade generally leads to increased synchronicity of the cyclical movements of the national economic time series. However, Imbs (1999) qualifies the main finding of Frankel and Rose (1998). His results tend to play down significantly the potential role of foreign trade in explaining the co-movement of national business cycle indicators. Instead, he finds that bilateral differences in the sectoral structure as well as bilateral differences in GDP are the main determinants of the degree of synchr onicity of national business cycles. Clark and Wincoop (2001) investigate the evidence of within-country and across-countries business cycle synchronicity for Europe and the U.S.

1 See among others Fatás (1997), p. 746, and Christodoulakis et al. (1995), p. 12. 
They identify a higher correlation of economic variables within the U.S. than within Europe and conclude that these differences are due to the existence of (national) borders in Europe. But some evidence seems to indicate that this border effect has become smaller in Europe in the 1980s.

This paper takes the above literature as a starting-point and tries to trace back the synchronicity of regional employment cycles to idiosyncratic sectoral developments within diffe rent Europe an regions. These regions are - as a stylised fact - characterised by the emergence of agglomer ations. That is, certain areas experience a change in their employment figures and at the same time economic activity becomes more or less concentrated in certain industry branches. This in turn has on the one hand a sustained impact on the regions' economic pe rformance and on the other hand the regional sectoral structure might differ in comparison to other regions. In order to examine the relationship between the similarities of regional sectoral structures and the fluctuations of the regional employment cycle, we intend to quantify changes of the regional sectoral structure caused by European integration over the last two decades. For this purpose, we construct a number of annual indices measuring the degree of similarity between the sectoral structures of two regions (in the following called "specialisation indices") for 30 European regions. It is generally acknowledged that a disaggregated representation of an employment cycle displays higher informational contents than its aggregated representation because different regional developments cancel out at the aggregated level. Moreover, the agglomeration phenomenon can be grasped more accurately by a higher resolution. Hence, we decided to follow Fatás (1997), Forni and Reichlin (1997) and Clark and Wincoop (2001) and focus on the regional instead of the national dimension.

However, our analysis differs from the above cited papers in several respects. First, and in contrast to Artis and Zhang, our procedure is not limited to the analysis of benchmark cycles. Instead, we correlate all possible region-pairs with each other. Second, we emph asise 
the regional dimension in the same way as Fatás (NUTS1) by using regional employment data. In this paper, however, we de-trend the latter with a more useful econometric filter technique. Third, we do not emphasise the role of nominal impact variables, such as the exchange rate regime, but focus on real variables, i.e. similarities in the sectoral structure, in determining the cyclical behaviour of the employment time series. Fourth, we dispense with investigating the correlation between regional cycles and national or European cycles. Instead, we focus on the impacts of a change in the regional sectoral pattern of production on the degree of correlation of regional employment cycles.

Nearly all contributions in this field investigate the sources of national co-fluctuations empirically, but only a small number (Fatás, 1997, Barrio s et al., 2001, Clark and Wincoop, 2001) delivers a detailed analysis at the regional level. However, studies which examine the relationship between regional sectoral patterns and the sy nchronicity of employment cycles for a wide range of European regions are not yet available. ${ }^{2}$ Since industry-specific shocks usually play a more important role at the regional than at the cross -national level (Clark and Shin, 2000), such studies would fill an existing gap in the literature. Closest to this demand is the study by Clark and Wincoop (2001) which identifies correlations between regional cycles based on border effects and on a measure of the similarities in the bilateral national instead of regional production patterns. In other words, their study contributes to filling this gap but still applies an identical economic structure for each region of the respective nation. As an innovation, we start with their methodology but focus on the bila teral similarities or differences in regional instead of national production patterns determining the synchronicity of the employment cycles between these regions.

\footnotetext{
One exception is the study by Barrios et al. (2001) who investigate the impact of sectoral specialis ation on the co-fluctuations among U.K. business cycles and on the co-fluctuations of the latter with EU country cycles.
} 
One branch of theory which tries to explain the choice of industries to locate in a certain region is the New Economic Geography literature, which explicitly conveys detailed theoretical information about the impact of increasing economic integration on the development of industrial structures. Moreover, this literature implicitly gives information about the resulting sectoral structures as well as about specialisation patterns. Under the scenario of increasing economic integration, there will be advantages for firms of one industry to cluster in a certain region - these agglomeration forces can be self-reinforcing ("cumulative caus ation") and will tend to encourage concentration of industrial activity. Centripetal or centrif ugal forces are commonly regarded as the main reasons for such cumulative causation (for a survey see, e.g., Krugman, 1998). These forces have a significant impact on the decision of mobile production factors to agglomerate or deglomerate geographically. Changes in the sectoral structure of the respective economy will be the result. However, centripetal or centrifugal forces themselves are determined by the degree of integration or, to be more precise, by the magnitude of transportation costs. Some features of the New Economic Geography are used in the next section to construct several indices to quantify the degree of similarity in the sectoral structures of two regions.

\section{Data and stylised facts}

In order to test the conjectured impact of the degree of similarity (regional specialisation patterns) on the synchronicity of regional employment cycles empirically we employ a panel of 30 European regions from six countries, namely Belgium, France, (West) Germany, Ireland, the Netherlands and Spain. The sample for the final regressions runs from 1989 to 1996. This specific choice of regions is determined by the current limitations of data avai lability. However, from an economic point of view this is sensible because these regions at least represent an area which has been called the core European Monetary Union (EMU). And for this core EMU the synchronicity of cycles as a precondition of a well-functioning 
currency union has been discussed exhaustively. From the data we were able to construct 435 region-pairs. These regions -pairs will later on represent the cross -sections for our panel regression analysis. The definition of regions used in this paper is based on the Nomenclature of Territorial Units for Statistics of EUROSTAT, namely the NUTS 1 level. ${ }^{3}$ The NUTS was established by EUROSTAT to provide comparable regional breakdowns of the Member States of the European Union. In Table 1, all European regions included in our empirical analysis are listed.

\section{- Tab. 1 about here -}

In the following, we determine the degree of employment cycle synchronicity and the degree of bilateral similarity in the sectoral structure of both regions for all of the regionpairs we can construct from the above listed regions.

\subsection{Synchronicity of regional employment cycles and bilateral regional specialisation patterns: specification and data}

In order to derive the degree of employment cycle synchronicity, the regional employment cycle for each European region is approximated by the de-trended time series of total regional employment. For the de-trending procedure the Hodrick-Prescott-Filter with parameter 10 is used in order to transform the non-stationary variable regional employment to a stationary one (see Hodrick and Prescott, 1997). ${ }^{4}$ The advantages of this standard practice are, first, that it is easy to implement and, second, that the resulting cyclical residuals are similar to those of the band-pass filter introduced by Baxter and King (1999). We use the regional employment data provided by EUROSTAT. These data are available for the Belgian regions for a time span ranging from 1975 to 1997, for the French, West German and Dutch regions as well as for Ir e-

\footnotetext{
We assume that Ireland is one region, and the reduction of the eleven West German regions to eight avoids using the so-called city-states in Germany.

4 Additionally, we conducted panel unit root tests which clearly rejected the non-stationarity for the gener-
} ated series. See section 3.2. 
land from 1970 to 1997 and for the Spanish regions from 1980 to 1997 . To quantify the synchronicity of the bilateral regional employment cycles we use the well-known Bravais-Pearson correlation coefficient between both cycles. We base the correlation coefficient on a rolling window with a reasonable size of five periods. ${ }^{5}$

In order to quantify the degree of similarity in bilateral regional production patterns and to use these results for our regressions in section 4 , we employ popular ind ices used by many scholars in the empirical literature. ${ }^{6}$ As an innovation, we do not focus on just one indicator. Instead and in order to conduct a "sensitivity analysis" our estimations are based on three alternative indices, each having its own merits. As a first indicator we use the index of conformity CON (Imbs, 1999). It is constructed analogously to the usual correlation coeff icient, but without consideration of the statistical mean. Its realisations lie between zero (the sectoral structure of both regions observed is totally different) and one (both regions have the same sectoral structure). A disadvantage of this indicator is that the value of the $r$ esults tends to be near one, even if there are significant differences in the sectoral structure between two regions. Hence, this index has to be interpreted rather cautiously.

Second, we use the Finger-Kreinin index FIN. ${ }^{7}$ It is defined as the sum of the minima of the sectoral shares of two regions. The higher the empirical realisation of this index (max imum 1), the more similar the sectoral structures between the two regions. Although this index compares two regions sector by sector, the strategy of summing up the minima might be a problem. For instance, the value of the index is unchanged when there are significant changes in the sectoral structure of one region but no changes in the minima.

5 See Inklaar and DeHaan (2001) who use just five periods to calculate the correlation coeff icients; for a ten-year window see, e.g., Caporale et al. (1999). In this paper, we dispense with using ten -year windows for constructing the rolling correlation coefficient (as, e.g., ECB, 1999) in order to avoid losing ten degrees of freedom. This would not be the case if monthly or higher frequency data were available. As an additional cross-check we also captured movements in synchronicity over time by recursive estimates of bilateral correlations in an earlier version of this paper. See Belke and Heine (2001).

6 Surveys of the advantages and disadvantages of such indicators are widespread and can be found in Krieger-Boden (1999), Midelfart-Knarvik et al. (2000) or WIFO (1999).

7 See, e.g., Finger and Kreinin (1979), Greenaway and Hine (1991), and Amiti (1997). 
The third and final index we employ is the specialisation coefficient SPEC. This was e.g. employed by Krugman (1991), Molle (1997), Clark and Wincoop (2001), Kim (1999) and OECD (1999). This index allows for realisations between zero (both regio ns have the same sectoral structure) and two (the sectoral structure of both regions observed is totally different). In a strictly verbal sense CON and FIN are measures of similarity since their empirical realisations grow with increasing similarity between sectors and only SPEC is an index of specialisation / diversification since its realisation shrinks with increasing similarity. Ho wever, all the indices we apply here try to measure the bilateral degree of similarity and qua ntify the regional specialisation patterns. The three indices employed are displayed and explained in Table 2.

\section{- Tab. 2 about here -}

A change in all of these specialisation indices can principally be put down to the fact that the relative shares of the sectors have changed. The more in dustrial sectors are available, the more meaningful the indicators are. In our case the number of available sectors might probably pose a slight problem but cannot be completely solved because of the limited data availability. In order to construct the dif ferent indicators we use the time series of the nominal regional gross value added for the 30 European regions, ranging from 1975 to 1996 for the Belgian regions, from 1975 to 1994 for the French and West German regions as well as for Ireland, from 1975 to 1993 for the Dutch regions and from 1980 to 1995 for the Spanish regions. Our choice of this variable significantly deviates from Imbs (1999) who estimates a specialisation index based on the sectoral total employment. We do not use employment data becaus e there is a lack of sectoral coverage of these data such that the specialisation index would not be very meaningful. In order to avoid such problems inherent in the use of an index of sectoral total employment, we use the regional gross value added for six different sectors (agricultural, forestry and fishery products, fuel and power products, manufac- 
tured products, building and construction, market services and non-market services). Unfortunately, European regional data do not yet allow a finer disaggreg ation of these data.

The lower the value of the index of conformity CON and the Finger-Kreinin index FIN, the higher is the degree of specialisation and, hence, the lower is the degree of simila rity between the two examined regions and as a result the co-fluctuation between the employment cycles must be very low. With respect to the coefficient of specialisation SPEC the contrary holds. According to the coefficients of the "specialisation indices" in our regressions explaining correlations coefficients of regional employment cycles, we expect the following conditions to hold:

$$
\begin{array}{lll}
\frac{\partial K O R}{\partial C O N}>0 ; & \frac{\partial K O R}{\partial F I N}>0 ; & \frac{\partial K O R}{\partial S P E C}<0 ; \\
0 \leq \mathrm{CON} \leq 1 & 0 \leq \mathrm{FIN} \leq 1 & 0 \leq \mathrm{SPEC} \leq 2
\end{array}
$$

with the variable KOR representing the Bravais-Pearson correlation coefficient measuring the five-year moving correlation between the residuals of Hodrick-Prescott (HP)-filtered employment of two regions. In other words, employment growth should be more synchronised when regions look more alike in their sectoral structure - for example, when manufacturing plays an important role in both regions, or when agriculture dominates. More specif ically, the higher the values of the index of conformity and the Finger -Kreinin index are, the more similar the sectoral structures are between the tw o examined regions and the higher the degree of synchronicity of the employment cycles should be. However, the contrary is valid for the coefficient of specialisation. The higher the value of SPEC, the less similar the sectoral structures between the two respective regions and the lower the synchronicity of the employment c ycles.

In addition to these different specialisation indices we complement our analysis by inclu ding selected additional variables. First, we experimented with a dummy variable to deal $\mathrm{w}$ ith 
the German unification in 1990 and dummies for common borders to capture ge ographic proximity. However, these variables were only included in a small number of cases in our preferred specification. Second, we include the difference in real income between two regions (see also Imbs, 1999) by taking the absolute value of the difference of the regional GDP deflated by the national consumer price index (annual data from 1975 to 1996). The time periods for the regional GDP data range from 1977 to 1996 for the Belgian regions, from 1980 to 1996 for the French and West German regions, from 1975 to 1996 for Ireland, from 1981 to 1996 for the Dutch regions and from 1980 to 1996 for the Spanish regions. We expect a negative sign of the estimated coefficient of the difference in real incomes, implying a higher correlation of employment cycles if incomes are more sim ilar.

\subsection{Stylised Facts}

A variety of stylised facts for business cycles is accepted as valid at the national level by many scholars, but for the regional level such relatively indisputable facts are missing. In particular, this could be caused by the fact that adequate regional time series are currently not available. First steps in this direction were undertaken by Fatás (1997) and Clark and Wincoop (2001). In their investigations they found out that the co-movements of economic variables between European regions are decreasing, but not to a statistically significant extent. On the contrary, the correlations of national cycles within Europe seem to incre ase significantly according to several studies. On a more general level, it seems fair to state that the following picture has emerged in the literature. Despite large regional policy expenditures, regional inequalities in Europe have not narrowed substantially over the last two decades, and according to some measures have even widened. European States have developed increasingly common production structures. But European regions have become increasingly 
polarised in terms of their employment performance. ${ }^{8}$ Seen on the whole, the puzzle of a decreasing synchronicity of within-country regional business cycles alongside with increased synchronicity of national cycles emerges. However, this puzzle can at least be partially solved by searching for possible impact factors (i.e., several specialisation indices) behind this negative regional trend in synchronicity.

In order to check the empirical validity of the above hypothesis we start with some simple scatter plots, presented in Figure 1. This figure shows cross -plots of each of our bi-regional measures for the specialisation indices (CON, FIN and SPEC) and of the bi-regional correlation coefficients of residuals of the HP-filtered regional employment for all region-pairs. All variables are averaged over the perio 1975 to 1997 (if available). In addition, we fit a tent ative bi-variate regression of the correlation coefficient on the specialis ation index and an intercept. The corresponding estimated regression line is represented by the straight line in each scatter plot. The least squares method, however, is very sensitive to the presence of a few outlying observations. For this reason we also carry out a form of weighted least squares where outlying observations are given less weight in estimating the regression c oefficients (see Cleveland, 1993).

\section{- Figure 1 about here -}

As expressed by the regression lines, the existence of the conjectured negative (positive) relationship between SPEC (CON and FIN) and the correlation coefficient of regional emplo yment growth cannot be rejected at first glance. However, the correlations indicated by the figures appear to be quite weak. Without taking into account additional variables, the extent of specialisation seems to have only weak explanatory power for the employment growth correla-

\footnotetext{
See Imbs (1998), Clark and Wincoop (2001), Kalemi-Ozcan et al. (2000). A recent paper by Puga (2002) describes these trends, and discusses how recent location theories can help us to explain them and to reconsider the role of regional policies, especially transport infrastructure improvements, in such an environment.
} 
tions. In the rest of this contribution we tackle this issue more fo rmally. We start our formal empirical analysis with tests of the non-stationarity of the levels and the first differences of the variables under consider ation. The test we apply here is the first widely used panel data unit root test by Levin and Lin (1992). ${ }^{9}$ As expected, the non-stationarity of the levels of all variables under investigation can be rejected in spite of the rather high (in absolute va lues) critical values of the test-statistics. This leads us to focus solely on the levels of the variables of interest, namely the correlation coefficient KOR, the relative income RELINC and the three different specialisation indices listed in section 3.1.

\section{Empirical evidence}

In order to test for a significant relationship between the correlation of regional EU employment cycles and the specialisation indices constructed for region-pairs, we run dynamic panel regressions of the correlation coefficient KOR between two regional employment cycles on its own past level, one of the measures of the degree of similarity, and a variable capturing relative differences with respect to regional income. ${ }^{10}$

\subsection{Empirical model and estimation procedure}

Based on our theoretical arguments we conjecture that a decreasing degree of regional similarity tends to reduce the correlation between EU regional employment cycles in a cross country panel analysis, after controlling for additional variables. To test for a significant negative impact of an increasing degree of specialis ation on the correlation between regional

\footnotetext{
9 This test was augmented by Levin and Lin (1992) and critically surveyed by Higgins and Zakrajsek (1999). It represents a direct extension of the univariate ADF test setting to panel data. The results by Levin and Lin indicate that panel data is particularly useful for distinguishing between unit roots and highly persistent stationarity in macroeconomic data and that their unit root test for panel data is appropriate in panels of moderate size as encountered in our study. For detailed results see Belke and Heine (2001).

10 If necessary, a dummy for German unification was included as well. We originally exper imented with dummies for common borders as well. However, these dummies did not enter the final specifications due to lack of significance and/or near singular matrix problems. In an earlier version of this paper, we also run regressions under the relatively rigid statistical assumption that all region-pairs in the pool react in the same manner to changes in the concentration measure. However, the results remained similar.
} 
employment cycles in the EU, we undertake fixed effects estimations, assuming region-pair specific intercepts and slope coefficients which are the same across units. Based on the ge neral-to-specific approach, the final specification of the underlying regression equations is reached according to the usual diagnostics (see, e.g., Wooldridge, 2003).

We exclusively estimate fixed effects models. ${ }^{11}$ However, in the literature random effects models are sometimes implemented instead of fixed effects models, mainly because the FE country-dummies are costly in terms of lost degrees of freedom. We decided to dispense with a random effects estimation because it would only be appropriate, if we really assumed that our sampled cross-sectional units were drawn from a large common population as is not the case here. The key distinction between fixed and random effects models is whether the individual effects should be treated as correlated with the x's or not. Correla tion would favour the estimation of a fixed effects model. No correlation would support a random effects estimation. In our case there is practically speaking little reason to treat the individual effects as uncorrelated with the other regressors as assumed in the random effects model. Moreover, in our context it is rather clear that fixed effects are likely to be more rigorous as will be discussed later (Greene, 2003, pp. 293ff., and Hsiao, 2002, pp. 149ff.).

For reasons of methodological correctness, we also performed Hausman specification tests to check empirically whether fixed effects is the correct estimation procedure (against the possible alternative of random effects). For this purpose, we compute the Hausman test st atistic for testing the null hypothesis of random effects against the alternative hypothesis of fixed effects (Hausman, 1978). Already having an eye on the final regression equ ations we are concerned with three specifications according to which the correlation coefficient KOR is a function of its own first and second lag, contemporaneous relative income and one of the three different measures of the bilateral similarity lagged one period. The results which

11 The time dimension of the data available for the EU regions is too small to get rel iable estimates from country-specific time-series regressions. 
reveal evidence in favour of a fixed effects estimation are displayed in Table 3. The null hypothesis that random effects is the better (i.e., unbiased) option is rejected according to the chi-squared tables at the usual significance levels throughout our specifications. ${ }^{12}$ Hence, we feel justified to dispense with random effects estimations and to focus on fixed effects models in the remaining part of the paper.

\section{- Table 3 about here -}

The empirical model we start with is the most common one and can be described as follows:

$$
y_{i t}=\alpha_{i}+x_{i t}^{\prime} \beta+\varepsilon_{i t},
$$

with $\mathrm{y}_{\mathrm{it}}$ as the dependent variable (synchronicity), $\mathrm{x}^{\prime}{ }_{\mathrm{it}}$ and $\beta$ as k-vectors of non-constant regressors (e.g., one of the specialisation indices CON or FIN or SPEC, the relative income RELINC and a dummy for German unification (DUMGER) and parameters for $i=1,2, \ldots$ , $N$ cross-sectional units and the periods $t=1,2, \ldots, T$ for which each cross-section is observed. The parameter $\beta$ has no subscript because our estimation procedure assumes that it is common to all units.

The corresponding setting with respect to a representative dynamic regression equ ation for one cross-section out of the whole system (described by the index i) is the following:

$$
y_{i t}=\alpha_{i}+x_{i t}^{\prime} \beta+\delta y_{i, t-1}+\varepsilon_{i t}
$$

When estimating our first-order model substantial complications might potentially have to be taken into account. This is due to the heterogeneity of the cross-sections analysed (Greene, 2000, pp. 582 ff.). The main problem to be treated in this context is the correlation of the lagged dependent variable (the correlation coefficient KOR lag ged one or more periods) with the disturbance, even if the latter does not exhibit autocorrelation itself. However,

\footnotetext{
12 We also experimented with estimations based on White standard errors and covariances and got strikingly similar results.
} 
the Nickell bias, i.e. the one found in the fixed effects model, is much less of a problem when the time dimension is large (Nickell, 1981). In fact we argue that the time dimension in our case is large enough to estimate by within groups, i.e. use the standard fixed effects estimator. We do not worry about instr umenting the lagged dependent variable, because in the present case the use of lags as instruments would look doubtful because measurement error and possibly the moving average nature of the variables tend to induce serial correlation in the error term. Hence, the standard FE estimator is not only simpler but also more rigorous in our case. Hence, we rely on the standard least squares FE estimates where all observations are given equal weight throughout our estimations. As an add itional robustness check, we also use the Feasible Generalized Least Squares (FGLS) estimates of the empir ical FE model assuming the presence of cross-sectional heteroscedasticity and autocorrelation but without correction for contemporaneous correlation. This neglect is no drawback since correlations across countries might only become relevant in the case of symm etric shocks to regional labour markets and the probability of the latter is typically small in our large EU sample. ${ }^{13}$ As usual, we call this kind of estimation procedure the cross-section weights case. It implies that each pool will have an unrestricted in tercept and that each pool equation is down-weighted by an estimate of the cross-section residual standard deviation.

\subsection{Results}

The original sample has been chosen to range from the year of the fall of the iron curtain 1989 to the year 1997. The decision in favour of this sample which fits the data best was taken with an eye on robustness with respect to German unification (with economic antic ipation effects felt already in 1989) and on the impact of this choice on the sample available for the so-called Wooldridge-test of serial correlation of residuals in dynamic panels which we use in our estimations. Due to the fact that this test implies a regression equ ation which

13 See the debate on optimum currency areas, e.g., Babetski et al. (2002). 
contains lagged residuals, the sample for the Wooldridge-test is diminished by one year and now comprises exactly the years in the wake of German economic and monetary union. Due to the fact that the indices used by us are available only up to 1996 the last year of the sample actually used is 1996. All of our representative final regression equation specifications which are displayed in Table 4 include two endogenous lagged correlation coefficient s KOR, the respective specialisation index (the index of conformity CON, the Finger-Kreinin index FIN or the coefficient of specialisation SPEC), and the variables relative income RELINC and, if significant, also the dummy for German unification DUMGER. With an eye on the annual frequency of the data, we limit possible lags to a number from 0 to 2 (annual data) and then test down until we arrive at the specification fitting best. The number of lags of the relevant variables are determined by the usual goodness -of-fit criteria for panels. By this procedure, we try to ensure that the dynamics of the model are sufficiently rich that s erial correlation of the residuals is eliminated.

The fit of each equation is checked by referring to the R-squared, the F-statistics and an AR(1) time series test for the autocorrelation of residuals. ${ }^{14}$ The latter test for autocorrelation of the residuals of order one is highly recommended by Wooldridge (2002) for dynamic panels, even if the latter include lagged endogenous variables. It regresses the dependent variable on the independent variable and the lag of residuals from the original equation. Based on this regression for 1990 to 1996, a standard t-test on the significance of the coefficient of the lagged pool residuals is performed. Under the null hypothesis, this coefficient is zero and, thus, there is no autocorrelation of the residuals. ${ }^{15}$ The empirical realization of the $\mathrm{t}$-statistics is displayed in Table 4 jointly with the corresponding p-value (denoted as $\hat{t}$ ). Since the marginal significance level of the F-test of joint significance of all slope coeffi-

14 See Wooldridge (2002), p. 176f. Serial correlation should not be present in a model which is supposed to be dynamically complete in the conditional mean.

15 A nice feature of the statistics computed is that it works whether or not the regressors are strictly exogenous. 
cients is in all cases clearly below one percent, the p-value is not explicitly tabulated by us. However, the degrees of freedom can be easily read off from the table. ${ }^{16}$ We expect positive signs of the estimated coefficients of the index of conformity CON and the Finger-Kreinin index FIN and a negative sign of the coefficient estimate of the coefficient of specialisation SPEC. We now turn to a final discussion of our representative estimations in T able 4.

\section{- Table 4 about here -}

Table 4 contains a rather strong result. Independent of the specific measure of the bilateral degree of similarity (the index of conformity CON, the Finger-Kreinin index FIN or the coefficient of specialisation SPEC), the estimated coefficients measuring the impact of the degree of similarity on the correlation between regional employment cycles in the EU are always significant at the one percent level. Moreover, the coefficient estimates always display the expected sign. The economic impact of the relative income on the degree of correlation between regional employment cycles originally claimed by Imbs (1999) is small but economically non-negligible. If cross-section weights are used, the estimated coefficients are slightly smaller but nevertheless highly significant with the expected sign. The dummy for German unification is significant in only a small number of cases. The available test statistics in the lower part of both tables point towards correct specifications of the final regression equ ations. Most important, according to the Wooldridge test statistics the dynamics of the final models are sufficiently rich that serial correlation of the residuals is absent. The lags of the dependent and/or explanatory variables appear to be long enough in this respect. The broad result that emerges from Table 4 is that the exact specification of the specialisation index does not really affect the role of the regional specialisation pattern for business cycle synchronis ation in general. Complementary investigations show that the use of covariances which are

\footnotetext{
16 The numerator degrees of freedom can be calculated as the number of explanatory var iables less one and the denominator degrees of freedom corresponds to the numbers of observations minus the number of $\mathrm{r}$ egressors.
} 
robust to general heteroscedasticity do not change our results. As well from this point of view, the results displayed in table 4 are quite representative.

Finally, we would like to stress a common feature of all estimation results, namely the fact that our specialisation indices enter most of the regression equations not contemporaneously but with a lag. This clear pattern underlines the validity of our prior that the measures of similarity are exogenous with respect to the correlation coefficient. However, a nice feature of the Wooldridge statistics computed to test for the absence of residual autocorrelation is anyway that it works whether or not the regressors are strictly exogenous .

\section{Summary and outlook}

This paper examines the degree of correlation in EU regional employment cycles and attempts to show whether this reflects changing patterns of specialisation. The approach taken in this paper is closest in spirit to Clark and Wincoop (1999) although it looks at regional rather than national indicators of similarity. With its focus on the regional level and by using three different indicators of similarity of sectoral structure, it goes beyond exis ting studies. The empirical method adopted is to estimate a dynamic panel data model for $r$ egion-pairs by within groups, i.e. a standard fixed effects estimator. Special attention is paid to ensure that the dynamics of the model are sufficiently rich that serial correlation is elim inated. The key finding is that employment growth is more synchronised in a statistical and econometric way when regions look alike in their sectoral structure. This finding is robust in two dimensions. First, in contrast to most of the empirical literature, we used three different indicators to approximate the regional sectoral structure. Since the results are not sens itive to the choice of the indicator, the relationship between the sectoral structure and the co-movement of employment cycles seems to be stable. Second, our key finding closely corr esponds with the results from Clark and Wincoop (2001) with the only exception, that they do not focus 
on and quantify the regional specialisation patterns. Instead, they just used a national index, therefore implicitly assuming, that regions are homogenous ent ities.

The section on stylised facts mentions that the degree of synchronicity of regional employment cycles has declined in the past for a majority of region-pairs. The evidence in favour of a decreasing synchronicity of regional employment cycles is implicitly backed by other studies with a regional focus (Fatás, 1997, Clark and Wincoop, 2001). This result is in contrast to many studies with a national focus (e.g., Barrios et al., 2001) which indicate an increasingly closer correlation of national business cycles between countries which are now members of EMU (e.g., Artis and Zhang, 1997 and Christodoulakis et al., 1995). In section 2 we called this a puzzle which is likely to be of fundamental importance in driving the results and is also important for the context in which we see this contribution. According to our estimation results, the trend decline of synchronicity of business cycles at the regional level could be explained mainly through changes in the sectoral structure, given the small impact of relative incomes. However, this paper can only potentially solve part of the puzzle, because it cannot explain why synchronicity between EU national cycles has grown at the same time. However, well-founded speculations in this direction could for instance start from the insight that the industrial structure of the EU countries as a whole represents an average of its different regional sectoral structures. Hence, industrial structures do not differ that much from each other on a national level as they do on a regional level by construction.

However, one should be careful and not draw premature conclusions from the quite consistent empirical results gained in this paper. Above all, one should not open discussions which risk to imply that low synchronisation of regional cycles is a problem when it could be optimal. According to the New Economic Geography literature, low synchronisation might instead just be an expression of agglomeration tendencies on a regional level which take place according to an optimising calculus. Centripetal or centrifugal forces which de- 
termine the degree of agglomeration are determined by the degree of integration or, to be even more concrete, by the magnitude of transportation costs. 


\section{References}

Amiti, M., 1997, Specialisation Patterns in Europe, Weltwirtschaftliches Archiv 135, 573 593.

Artis, M. J. and W. Zhang, 1997, International Business Cycles and the ERM: Is there a European Business Cycle?, International Journal of Finance and Econo mics 2, 1-16.

Babetski, J., L. Boone and M. Maurel, 2002, Exchange Rate Regimes and Supply Shocks Asymmetry: The Case of the Accession Countries, CEPR Discussion Paper No. 3408, Centre for Economic Policy Research, London.

Barrios, S., M. Brülhart, R. Elliott and M. Sensier, 2001, A Tale of Two Cycles : Cofluctuations between UK Regions and the Euro Zone, University of Nottingham research paper series, Nr. 02/2001.

Baxter, M. and R. G. King, 1999, Measuring Business Cycles: Approximate Band-Pass Filters for Economic Time Series, Review of Economics and Statistics 81, 575-593.

Belke, A. and J. M. Heine, 2001, On the Endogeneity of an Exogenous OCA-Criterion: The Impact of Specialisation on the Synchronisation of Regional Business Cycles, HWWA Discussion Paper No. 119, HWWA-Institute for Economic Research Hamburg.

Brülhart, M., 2002, Labour-Market Effects of Intra-Industry Trade: Evidence for the United Kingdom, Weltwirtschaftliches Archiv 138, 207-228.

Caporale, G. M., N. Pittis and K. Prodromidis, 1999, Is Europe an Optimum Cu rrency Area? Business Cycles in Europe, Journal of Economic Integration 14, 169-202.

Christodoulakis, N., S. P. Dimelis and T. Kollintzas, 1995, Comparisons of Business Cycles in the EC: Idiosyncrasies and Regularities, Economica 62, 1-27. 
Clark, T. E. and K. Shin, 2000, The Sources of Fluctuations within and across Cou ntries, in:

Hess, G. and E. van Wincoop, eds., Intranational Macroeconomics, Cambridge University Press, $189-217$.

Clark, T. E. and E. van Wincoop, 2001, Borders and Business Cycles, Journal of Intern ational Economics 55, 59-85.

Cleveland, W. S., 1993, Visualizing Data, Hobart Pres s.

European Central Bank, 1999, Monthly Bulletin, July, Frankfurt, 35-58.

Fatás, A., 1997, Countries or Regions? Lessons from the EMS Experience, European Ec onomic Review 41, 743-751.

Finger, J. M. and M. E. Kreinin, 1979, A Measure of 'Export Similarity' and its Possible Uses, Economic Journal 89, 905-912.

Forni, M. and L. Reichlin, 1997, National Policies and Local Economies: Europe and the United States, CEPR Discussion Paper No. 1632, Centre for Economic Policy Research, London.

Frankel, J. A. and A. K. Rose, 1998, The Endogeneity of the Optimum Currency Area Crit eria, The Economic Journal 108, 1009-1025.

Greene W.H., 2000, Econometric Analysis, $4^{\text {th }}$ ed., New Jersey.

Greene, W.H., 2003, Econometric Analysis, $5^{\text {th }}$ ed., New Jersey.

Greenaway, D. and R. C. Hine, 1991, Intra-Industry Specialization, Trade Expansion and Adjustment in the European Economic Space, Journal of Common Market Studies 29, 603622.

Hausman, J., 1978, Specification Tests in Econometrics, Econometrica 46, $1251-1271$. 
Higgins, M. and E. Zakrajsek, 1999, Purchasing Power Parity: Three Stakes Through the Heart of the Unit Root Null, Federal Reserve Bank of New York, mimeo.

Hodrick, R. J. and E. C. Prescott, 1997, Postwar U.S. Business Cycles: An Empirical Inve stigation, Jounral of Money, Credit and Banking 29, 1-16.

Hsiao, C., 2002, Analysis of Panel Data, Cambridge.

Imbs, J., 1999, Co-Fluctuations, CEPR Discussion Paper No. 2267, Centre for Economic Policy Research, London.

Inklaar, R. and J. DeHaan, 2001, Is There Really a European Busines s Cycle?, Oxford Economic Papers 53, 215-220.

Kim, S., 1999, Expansion of Markets and Geographic Distribution of Economic Activities: The Trends in US Regional Manufacturing Structure, 1860-1987, Quarterly Journal of Ec onomics 110, 881-908.

Krieger-Boden, Ch., 1999, Nationale und regionale Spezialisierungsmuster im europäischen Integrationsprozess, Die Weltwir tschaft 2, 234-254.

Krugman, P., 1991, Increasing Returns and Economic Geography, Journal of Political Economy 99, 483-499.

Krugman, P., 1998, What's New about the New Economic Geography, Oxford Review of Economic Policy 14, 7-17.

Levin, A. and C.-F. Lin, 1992, Unit Root Tests in Panel Data: Asymptotic and FiniteSample Properties, University of California, San Diego, Department of Economics Discu ssion Paper 92-23, May. 
Midelfart-Knarvik, K. H., H. G. Overman, S. J. Redding, and A. J. Venables, 2000, The Location of European Industry, CEPR Discussion Paper Nr. 2618, Centre for Economic Policy Research, London.

Molle, W., 1997, The Regional Economic Struc ture of the European Union: An Analysis of Long-Run Developments, in: Peschel, K., ed., Regional Growth and Regional Policy within the Framework of European Integration, Heidelberg, 66-86.

Nickell, S., 1981, Biases in Dynamic models with Fixed Effects, Eco nometrica 49, 14171426.

OECD, 1999, EMU: Facts, Challenges and Policies, Paris.

Puga, D., 2002, European Regional Policies in Light of Recent Location Theories, Journal of Economic Geography 2, 373-406.

Quantitative Micro Software, 2000, EViews - Command and Programming Reference, Irvine, California.

WIFO, 1999, Specialisation and (Geographic) Concentration of European Manufacturing, Austrian Institute for Economic Research, Report of a Study for the Enterprise DG of the European Commission, Brussels.

Wooldridge, J. M., 2002, Econometric Analysis of Cross-Section and Panel Data, MIT Press, Cambridge, Mass. 


\section{Variable annex}

KOR: Bravais-Pearson correlation coefficient measuring the five-year moving correlation between the residuals of HP-filtered employment of two regions.

CON: $\quad$ Index of conformity as defined in Table 2.

SPEC: $\quad$ Finger-Kreinin index as defined in Table 2.

FIN: $\quad$ Coefficient of specialis ation as defined in Table 2.

RELINC: Relative income for a region-pair, calculated as the absolute value of the difference between the logarithms of real GDP of these two regions. Nominal regional GDP was deflated by the consumer price index of the country the respective regions belong to.

DUMGER: Dummy for German unification coded as 1 for the period from 1990 on, otherwise 0.

Data sources and more detailed specifications of each variable are described in section 3. 
Figure 1: Regional employment growth and regional degree of similarity in the $E U$

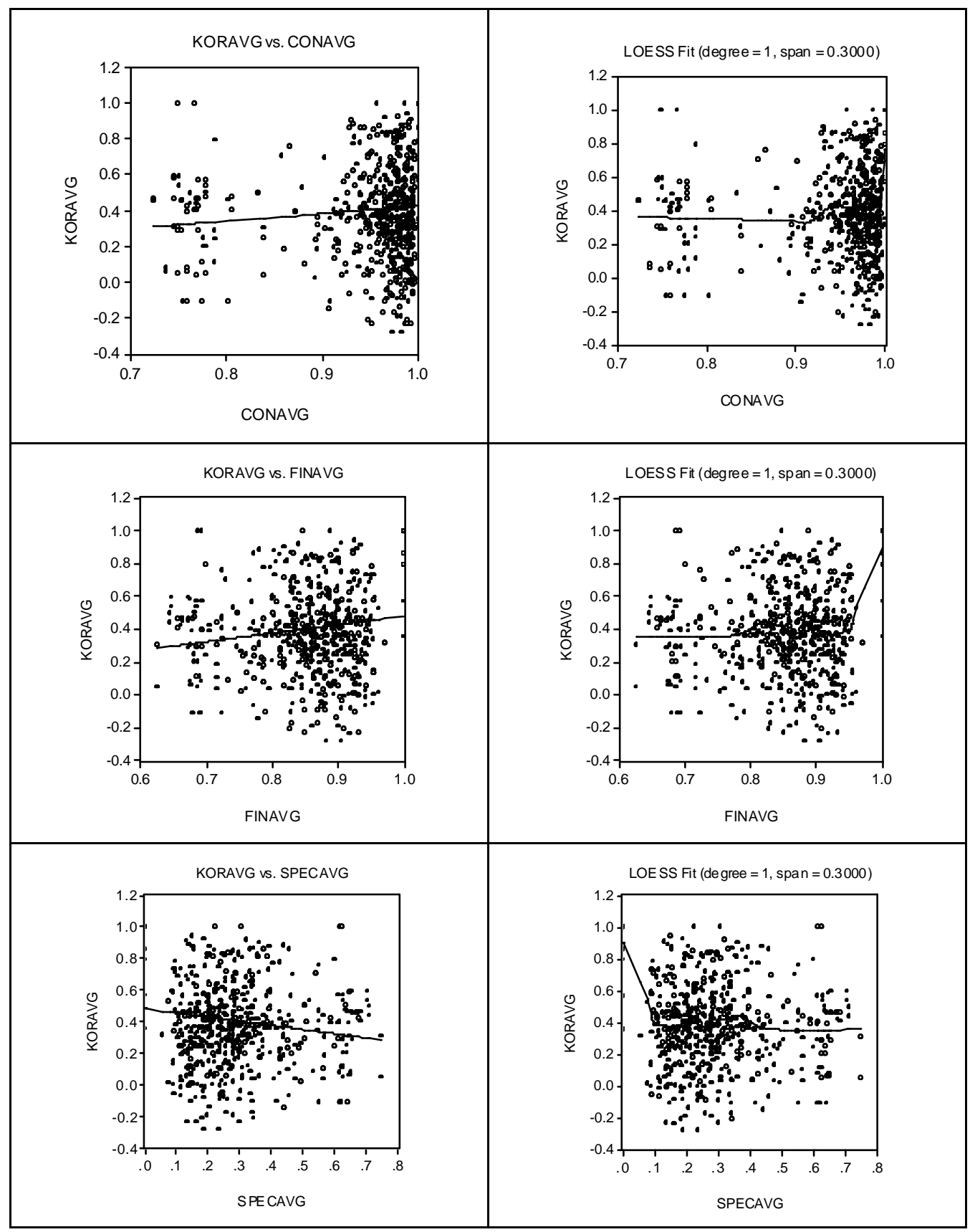

Note: The plots display arithmetic averages (AVG) of the respective variables over the whole sample from 1975 to 1997, if available. LOESS indicates the popular Loess (or LOWESS) techniques for local polynomial regressions with bandwidth based on nearest neighbours described, e.g., in Cleveland (1993) . 
Table 1: European NUTS 1 Regions: A Survey

\begin{tabular}{|c|c|c|}
\hline Region & $\begin{array}{c}\text { Nomenclature EURO- } \\
\text { STAT }\end{array}$ & $\begin{array}{c}\text { Nomenclature } \\
\text { used in this paper }\end{array}$ \\
\hline \multicolumn{3}{|c|}{ BELGIUM } \\
\hline RÉGION BRUXELLES- CAP. & BE 1 & $\mathrm{BE} 1$ \\
\hline VLAAMS GEWEST & $\mathrm{BE} 2$ & $\mathrm{BE} 2$ \\
\hline RÉGION WALLONE & BE 3 & $\mathrm{BE} 3$ \\
\hline \multicolumn{3}{|c|}{ France } \\
\hline ÎLE DE FRANCE & FR 1 & FR 1 \\
\hline BASSIN PARISIEN & FR 2 & FR 2 \\
\hline NORD-PAS-DE-CALAIS & FR 3 & FR 3 \\
\hline EST & FR 4 & FR 4 \\
\hline OUEST & FR 5 & FR 5 \\
\hline SUD-OUEST & FR6 & FR6 \\
\hline CENTRE-EST & FR 7 & FR 7 \\
\hline MÉDITERRANÉE & FR 8 & FR 8 \\
\hline \multicolumn{3}{|c|}{ Germany } \\
\hline SCHLESWIG-HOLSTEIN & DE F & \multirow{2}{*}{ G 1} \\
\hline HAMBURG & DE 6 & \\
\hline NIEDERSACHSEN & DE 9 & \multirow{2}{*}{ G 2} \\
\hline BREMEN & DE 5 & \\
\hline NORDRHEIN-WESTFALEN & DE A & G 3 \\
\hline HESSEN & DE 7 & G 4 \\
\hline RHEINLAND-PFALZ & DE B & \multirow{2}{*}{ G 5} \\
\hline SAARLAND & $\mathrm{DEC}$ & \\
\hline BADEN-WÜRTtEMBERG & DE 1 & G 6 \\
\hline BAYERN & DE 2 & G 7 \\
\hline BERLIN & DE 3 & G 8 \\
\hline \multicolumn{3}{|c|}{ Ireland } \\
\hline IRLAND & IE & IRL \\
\hline \multicolumn{3}{|c|}{ Netherlands } \\
\hline NOORD -NEDERLAND & NL 1 & NL 1 \\
\hline OOST- NEDERLAND & NL 2 & NL 2 \\
\hline WEST- NEDERLAND & NL 3 & NL 3 \\
\hline ZUID- NEDERLAND & NL 4 & NL 4 \\
\hline \multicolumn{3}{|c|}{ Spain } \\
\hline NOROESTE & ES 1 & ESP 1 \\
\hline NORESTE & ES 2 & ESP 2 \\
\hline COMUNIDAD DE MADRID & ES 3 & ESP 3 \\
\hline CENTRO (E) & ES 4 & ESP 4 \\
\hline ESTE & ES 5 & ESP 5 \\
\hline SUR & ES 6 & ESP 6 \\
\hline CANARIS & ES 7 & ESP 7 \\
\hline
\end{tabular}

Source: EUROSTAT (1999). 
Table 2: Indicators to quantify the degree of similarity in regional sectoral structures

\begin{tabular}{|l|c|c|}
\hline \multicolumn{1}{|c|}{ Indicator } & Formula & Range \\
\hline Index of conform ity & $\mathrm{CON}=\frac{\sum_{i=1}^{n} a_{i} \cdot b_{i}}{\sqrt{\left[\left[\sum_{i=1}^{n} a_{i}^{2}\right] \cdot\left[\sum_{i=1}^{n} b_{i}^{2}\right]\right]}}$ & 0 to 1 \\
\hline Finger-Kreinin index & $\mathrm{FIN}=\sum_{i=1}^{n} \min \left[a_{i} ; b_{i}\right]$ & 0 to 1 \\
\hline Coefficient of specialisation & $\mathrm{SPEC}=\sum_{i=1}^{n}\left|a_{i}-b_{i}\right|$ & 0 to 2 \\
\hline
\end{tabular}

Note: The variable $\mathrm{n}$ corresponds to the amount of sectors, $\mathrm{a}_{\mathrm{i}}$ is the share of sector $\mathrm{i}$ in country $\mathrm{A}$ and $\mathrm{b}_{\mathrm{i}}$ is the share of sector i in country B. 
Table 3: Hausman tests for fixed versus random effects (1989-1996)

\begin{tabular}{lll}
\hline Measure of specialisation used & Test statistics & Empirical realisation \\
\hline Index of conformity (CON) & chi-sqr(4) $=$ & 1085.459 \\
& p-value $=$ & 0.00 \\
Finger-Kreinin index (FIN) & chi-sqr(4) $=$ & 1066.93 \\
& p-value $=$ & 0.00 \\
Coefficient of specialisation (SPEC) & chi-sqr(4) $=$ & 1066.11 \\
& p-value $=$ & 0.00 \\
\hline
\end{tabular}

Numbers in brackets refer to the degrees of freedom of the Chi-square statistics. Estimations are in each case based on a least squares estimation of an equation which specifies the correlation coefficient KOR as a function of its own first and second lag, contemporaneous relative income and one of the three different measures of specialisation lagged one period. 
Table 4: Impact of the degree of specialisation on the correlation between regional employment cycles in the EU

(1)

(2)

(3)

(4)

(5)

(6)

Estimation method:

Fixed effects + no weighting

Fixed effects + cross-section weights

Regressors:

Correlation coefficient KOR

lagged one period

Correlation coefficient KOR

lagged two periods

Coefficient of specialisation:

\begin{tabular}{|c|c|c|c|c|c|c|}
\hline CON & $4.63 * * *(-1)$ & $4.37 * * *(-1)$ & I & I & 1 & I \\
\hline FIN & I & l & $2.25 * * *(-1)$ & $2.03 * * *(-1)$ & 1 & \\
\hline SPEC & I & I & I & I & $-1.10 * * *(-1)$ & $-1.00^{* * * *(-1)}$ \\
\hline Relative income (RELINC) & $-9.84 \mathrm{E}-05^{* * *}$ & $-0.0001 * * *$ & $-9.64 \mathrm{E}-05 * * *$ & $-0.0001 * * *$ & $-9.63 \mathrm{E}-05 * * *$ & $-0.0001 * * *$ \\
\hline \multicolumn{7}{|l|}{ (Weighted) statistics: } \\
\hline $\mathrm{R}^{2}$ & 0.66 & 0.97 & 0.66 & 0.97 & 0.66 & 0.97 \\
\hline F-statistics & 11.05 & 188.97 & 10.99 & 196.94 & 10.99 & 197.32 \\
\hline Wooldridge $-\hat{t}$ (p-value) & $-0.48(0.63)$ & $-0.12(0.90)$ & $-1.12(0.26)$ & $-0.70(0.49)$ & $-1.12(0.26)$ & $-0.67(0.50)$ \\
\hline
\end{tabular}

Each estimation uses 2956 total panel observations and 435 cross -sections. The sample in each case is 1989-1996. Numbers in brackets indicate the lag of the implemented regressor. If not otherwise indicated the variable is inserted con temporaneously. / means that the variable is not included. ***, **, * indicate significance at the 1,5 and 10 percent levels respectively.
$\mathrm{X}$

$\begin{array}{cc}0.55 * * * & 0.52 * * * \\ -0.30 * * * & -0.23 * * *\end{array}$

$0.56 * * *$

$0.53 * * *$

$0.56 * * *$

$0.53^{* * * *}$

$-0.30 * * *$

$-0.23 * * *$

$-0.30 * * *$

$-0.23 * * *$

X

/

$* *$

